\title{
Caracterização físico-química de amostras de méis produzidas por Apis mellifera L. em fragmento de cerrado no município de Itirapina, São Paulo
}

\author{
Physicochemical characterization of honey samples produced by Apis mellifera L. in a fragment of \\ savannah area in Itirapina county, São Paulo State, Brazil
}

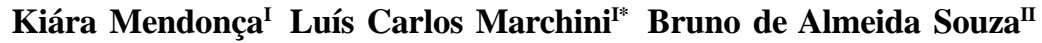 \\ Daniela de Almeida-Anacleto ${ }^{\mathrm{I}}$ Augusta Carolina de Camargo Carmello Moreti ${ }^{\mathrm{II}}$
}

\section{RESUMO}

A fisionomia vegetal mais representativa do país, depois da floresta amazônica, é o cerrado, que ocupa atualmente dois milhões de $\mathrm{km}^{2}$ do território brasileiro. Este trabalho teve como objetivo determinar as características físicoquímicas de amostras de mel produzidas por Apis mellifera em um fragmento de cerrado, localizado em Itirapina, SP (22 $14^{\prime}$ 'S e $47^{\circ} 49^{\prime} \mathrm{W}$ ). As amostras foram coletadas mensalmente, em cinco colméias, entre fevereiro e outubro de 2005 e as características avaliadas foram: açúcares redutores, redutores totais, sacarose, umidade, hidroximetilfurfural (HMF), cor, condutividade elétrica, $\mathrm{pH}$, acidez, índice de formol, teor de cinzas, proteínas e viscosidade, além da análise polínica. Os resultados obtidos indicam que os limites estabelecidos pela legislação brasileira para parâmetros físico-químicos analisados são atendidos pela maioria das amostras de mel. Com relação à análise polínica, foi verificada a presença de Eucalyptus sp. como pólen dominante nos meses de fevereiro a julho e o de Citrus sp. no mês de outubro, em virtude da maior atratividade destes dois cultivos sobre as abelhas.

Palavras-chave: Apidae, Apis mellifera, cerrado, legislação brasileira, qualidade de mel.

\section{ABSTRACT}

The most representative vegetation type of the country after the Amazonian forest is the "cerrado" (savannah) area, which currently occupies two million square kilometer of the Brazilian territory. This paper deals with the physicochemical characteristics of honey samples produced by Apis mellifera in a fragment of savannah area located in Itirapina, São Paulo State (22 $14^{\prime} \mathrm{S}$ and $\left.47^{\circ} 49^{\prime} \mathrm{W}\right)$, Brazil. The samples were collected monthly, in five beehives, from February to October 2005 and the following characters were determined: reducing sugars, total reducing sugars, apparent sucrose, moisture content, hydroxymethylfurfural (HMF), color, electrical conductivity, $\mathrm{pH}$, acidity, formol index, ashes, protein and viscosity, beyond the pollinic analysis. The results indicate that the limits established by the current Brazilian honey legislation regarding physicochemical parameters are fulfilled by the majority of the honey samples. Regarding pollinic analysis it was verified the Eucalyptus sp. as dominant pollen from February to July, and of Citrus sp. in October, due to the attractiveness of these two crops to the foraging bees.

Key words: Apidae, Apis mellifera, savannah area, Brazilian legislation, honey quality.

\section{INTRODUÇÃO}

O cerrado tem a fisionomia vegetal mais representativa do Brasil depois da floresta Amazônica e ocupa atualmente dois milhões de $\mathrm{km}^{2}$. Esse ecossistema encontra-se fragmentado e degradado pelo avanço das cidades e da agropecuária, representando, em São Paulo, apenas 1\% da área do Estado (FIORI \& FIORAVANTI, 2001).

A utilização de estratégias de conservação desse ecossistema tropical envolve necessariamente alternativas de uso que permitam o retorno econômico, as quais devem objetivar a obtenção de produtos que possam ser repostos pelo próprio ecossistema, num ciclo definido, possibilitando renda aos proprietários da terra e ao mesmo tempo mantendo o equilíbrio desejado destes ambientes (REIS \& MARIOT, 1999).

\footnotetext{
IDepartamento de Entomologia, Fitopatologia e Zoologia Agrícola, Escola Superior de Agricultura "Luiz de Queiroz” (ESALQ), 13418-900, Piracicaba, SP, Brasil. E-mail: lcmarchi@esalq.usp.br. *Autor para correspondência.

IINUPA (Núcleo de Pesquisa com Abelhas), Embrapa Meio Norte, 64006-220, Teresina, PI, Brasil.

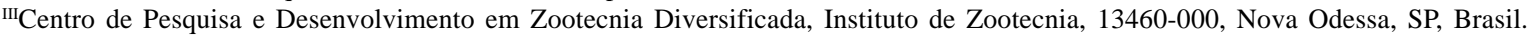


Dentro dessa perspectiva, a atividade apícola é uma das que mais tem se destacado.

A composição e as características do mel, como sabor, aroma, coloração, densidade e propensão à cristalização, variam de acordo com a flora local, pois estão relacionadas aos componentes presentes no néctar das diversas flores, assim como à proporção em que estão presentes (WHITE JÚNIOR, 1978).

Este trabalho teve o objetivo de determinar as características físico-químicas de amostras de méis produzidas por Apis mellifera em um fragmento de cerrado do Estado de São Paulo, contribuindo para a caracterização e a padronização dos méis brasileiros.

\section{MATERIAL E MÉTODOS}

O presente trabalho foi realizado em um fragmento de cerrado, localizado no município de Itirapina, Estado de São Paulo (22 $2^{\circ} 14^{\prime}$ S e $47^{\circ} 49^{\prime} \mathrm{W}$ ), apresentando altitude média de $760 \mathrm{~m}$ e solo do tipo Latossolo Vermelho Amarelo fase rasa (GIANOTTI, 1988). A região apresenta clima úmido com inverno seco, precipitação anual média de $1425 \mathrm{~mm}$, temperatura média de $19,7^{\circ} \mathrm{C}$ e clima classificado como Cwa de Köeppen. A área pertence à Estação Experimental de Itirapina, unidade da Divisão de Florestas e Estações Experimentais do Instituto Florestal, e apresenta cobertura vegetal correspondente a $68,9 \%$ de vegetação natural aproximadamente, representada em sua maior parte por fragmentos de cerrado em todas as suas formas fisionômicas, que fazem limite com áreas de floresta implantada com Eucalyptus e Pinus, e plantios comerciais de Citrus.

As amostras de méis foram colhidas mensalmente em cinco colônias de A. mellifera habitando caixas do tipo Langstroth, entre o período de fevereiro e outubro de 2005. Para que não ocorresse a mistura do mel produzido nos diferentes meses de colheita, foi adotado o critério de fornecimento de quadros de melgueira marcados, previamente trabalhados pelas abelhas (alvéolos já construídos) e vazios, que eram colhidos quando operculados e repostos a cada mês.

Os favos colhidos foram encaminhados ao Laboratório de Insetos Úteis do Departamento de Entomologia, Fitopatologia e Zoologia Agrícola da Escola Superior de Agricultura "Luiz de Queiroz", Campus de Piracicaba, da Universidade de São Paulo, para extração e beneficiamento. As amostras de cada mês foram homogeneizadas para formar uma amostra única, representativa do mês em que foi colhida, critério utilizado em virtude da proximidade das colônias e para a obtenção de um volume suficiente para a realização de todas as análises programadas.
As seguintes análises físico-químicas foram realizadas em triplicata: açúcares redutores, redutores totais e sacarose (COPERSUCAR, 1987 modificado por MARCHINI et al., 2004), umidade (ATAGO, 1988), hidroximetilfurfural (HMF) (AOAC, 1990), cor (VIDAL \& FREGOSI, 1984), condutividade elétrica (BOE, 1986), $\mathrm{pH}$, acidez e índice de formol (MORAES \& TEIXEIRA, 1998), teor de cinzas (PREGNOLATO \& PREGNOLATO, 1985), proteínas (SILVA \& QUEIROZ, 2002) e viscosidade (CAMPOS, 1998). Análise polínica das amostras também foi realizada com a finalidade de determinar as espécies vegetais que mais contribuíram para a formação da amostra de mel (ERDTMAN, 1952).

\section{RESULTADOS E DISCUSSÃO}

Os resultados das análises físico-químicas e dos tipos polínicos encontrados nas amostras de méis, bem como os valores de referência estabelecidos pela legislação vigente (BRASIL, 2000) são apresentados nas tabelas 1 e 2 . Embora a legislação brasileira não defina valores de referência para açúcares redutores totais, condutividade elétrica, $\mathrm{pH}$, índice de formol, proteína e viscosidade, estas análises foram realizadas e os resultados obtidos ajudam a complementar a caracterização deste mel.

As amostras analisadas apresentaram predominância da cor âmbar claro (66,7\%), seguida das cores âmbar (22,2\%) e âmbar extra-claro (11,1\%) (Tabela 1 e Figura 1). Estas classes de cores encontradas estão em conformidade com a legislação, que considera aceitáveis variações de branco d'água a âmbar escuro (BRASIL, 2000).

A predominância da cor âmbar claro também foi observada para méis argentinos (UÑATES et al., 1999), italianos (PERSANO-ODDO et al., 1995) e em méis brasileiros oriundos do Estado de São Paulo (MARCHINI, 2001), do Ceará e do Piauí(SODRÉ, 2005). Essa classe de cor também foi encontrada como predominante em amostras de méis produzidas em áreas de cerrado do Estado do Mato Grosso do Sul (VIEIRA, 2005) e São Paulo (ALMEIDA-ANACLETO \& MARCHINI, 2004).

As porcentagens de açúcares redutores obtidas variaram de 60,9 a $71,5 \%(67,4 \pm 3,4 \%)$, com a média dos resultados acima do valor mínimo (65,0\%) considerado como aceitável pela legislação (BRASIL, 2000). Duas dessas amostras apresentaram valores abaixo deste mínimo, podendo indicar um mel que ainda se encontrava em processo de amadurecimento no interior da colônia. Diversos trabalhos (SODRÉ, 2005; VIEIRA, 2005; ARRUDA, 2003; KOMATSU et al., 2002) mostram maior variação no teor de açúcares redutores 
Tabela 1 - Cor, tipos polínicos e valores médios de açúcares (redutores, redutores totais e sacarose), hidroximetilfurfural e umidade determinados em méis produzidos por Apis mellifera, no período de fevereiro a outubro de 2005, em fragmento de cerrado no município de Itirapina-SP.

\begin{tabular}{|c|c|c|c|c|c|c|c|}
\hline Mês de coleta & Cor & Tipos polínicos & $\mathrm{AR}^{*}(\%)$ & $\mathrm{ART}^{* *}(\%)$ & Sacarose (\%) & $\begin{array}{l}\mathrm{HMF}^{* * *} \\
\left(\mathrm{mg} \mathrm{kg}^{-1}\right)\end{array}$ & Umidade (\%) \\
\hline 02 & Âmbar claro & Eucalyptus sp. (pd) & 66,5 & 68,1 & 1,6 & 12,2 & 18,7 \\
\hline 03 & Âmbar claro & Eucalyptus sp. (pd) & 68,2 & 69,6 & 1,3 & 19,1 & 17,2 \\
\hline 04 & Âmbar claro & Eucalyptus sp. (pd) & 69,3 & 68,9 & 0,4 & 10,6 & 17,1 \\
\hline 05 & Âmbar claro & Eucalyptus sp. (pd) & 67,2 & 67,7 & 0,5 & 4,2 & 17,0 \\
\hline 06 & Âmbar & Eucalyptus sp. (pd) & 63,7 & 67,4 & 3,5 & 11,4 & 16,5 \\
\hline 07 & Âmbar & Eucalyptus sp. (pd) & 60,9 & 64,2 & 3,2 & 7,6 & 19,5 \\
\hline \multirow[t]{2}{*}{08} & Âmbar claro & Eucalyptus sp. (pa) & & & & & \\
\hline & & Serjania sp. (pa) & 69,1 & 71,4 & 2,2 & 5,7 & 16,4 \\
\hline \multirow[t]{3}{*}{09} & Âmbar claro & Eupatorium sp. (pa) & & & & & \\
\hline & & Eucalyptus sp. (pa) & 71,5 & 73,1 & 1,5 & 2,0 & 15,8 \\
\hline & & Serjania sp. (pa) & & & & & \\
\hline 10 & Âmbar claro & Citrus sp. (pd) & 70,6 & 72,1 & 1,4 & 1,9 & 16,7 \\
\hline Média & & & 67,4 & 62,2 & 1,7 & 8,3 & 17,2 \\
\hline Desvio padrão & & & 3,4 & 2,7 & 1,1 & 5,6 & 1,2 \\
\hline $\begin{array}{l}\text { Normas } \\
\text { (BRASIL, 2000) }\end{array}$ & & & Mín. 65,0 & --- & Máx. 6,0 & Máx. 60,0 & Máx. 20,0 \\
\hline
\end{tabular}

*AR= açúcares redutores; **ART= açúcares redutores totais; ***HMF= hidroximetilfurfural; pa= pólen acessório; pd= pólen dominante.

(53,2 a 87,3\%) em comparação com a variação observada no presente trabalho.

Para açúcares redutores totais, os valores obtidos variaram de 64,2 a 73,1\% (69,2 $\pm 2,7 \%)$, estando próximos aos encontrados para méis produzidos em Minas Gerais e Santa Catarina (CAMPOS, 1998), no Estado de São Paulo (MARCHINI, 2001), e em méis do Ceará (SODRÉ, 2005), que obtiveram uma variação de 58,4 a 81,9\%. Em área de cerrado do Mato Grosso do
Sul, foi obtida uma variação muito maior $(58,4$ a $91,9 \%$ para açúcares redutores totais) (VIEIRA, 2005).

Os teores de sacarose variaram de 0,4 a $3,5 \%$ $(1,7 \pm 1,1 \%)$ com valores abaixo da norma vigente que considera aceitáveis índices de, no máximo, 6,0\%. Valores extremos encontrados na literatura foram obtidos para amostras do Estado de São Paulo com variação de 0,1 a 15,2\% para méis de eucalipto e de 0,2 a 27,4\% para silvestres (MARCHINI, 2001).

Tabela 2 - Valores médios de condutividade elétrica, pH, acidez, índice de formol, cinzas, proteína e viscosidade determinados em méis produzidos por Apis mellifera, no período de fevereiro a outubro de 2005, em fragmento de cerrado no município de Itirapina-SP.

\begin{tabular}{|c|c|c|c|c|c|c|c|}
\hline Mês de coleta & $\begin{array}{l}\text { Condutividade } \\
\text { elétrica }(\mu S)\end{array}$ & $\mathrm{pH}$ & $\begin{array}{c}\text { Acidez } \\
(\text { meq kg-1) }\end{array}$ & $\begin{array}{l}\text { Índice de formol } \\
\quad\left(\mathrm{mL} \mathrm{kg}^{-1}\right)\end{array}$ & $\begin{array}{l}\text { Cinzas } \\
(\%)\end{array}$ & $\begin{array}{l}\text { Proteína } \\
\text { (\%) }\end{array}$ & $\begin{array}{l}\text { Viscosidade } \\
\text { (mPa.s) }\end{array}$ \\
\hline 02 & 1095,7 & 4,3 & 33,3 & 9,3 & 0,54 & 0,59 & 1070,0 \\
\hline 03 & 1428,3 & 4,6 & 28,3 & 9,3 & 0,72 & 0,57 & 2683,3 \\
\hline 04 & 1851,3 & 4,9 & 23,3 & 9,0 & 1,02 & 0,98 & 2636,7 \\
\hline 05 & 1744,3 & 4,9 & 24,7 & 11,7 & 0,85 & 0,66 & 3536,7 \\
\hline 06 & 1220,0 & 4,7 & 37,0 & 15,3 & 0,71 & 0,81 & 3550,0 \\
\hline 07 & 1334,7 & 4,3 & 47,0 & 16,7 & 0,57 & 0,74 & 1123,3 \\
\hline 08 & 547,0 & 4,3 & 24,3 & 7,0 & 0,20 & 0,58 & 2863,3 \\
\hline 09 & 283,7 & 4,0 & 15,1 & 8,4 & 0,06 & 1,00 & 4546,7 \\
\hline 10 & 227,3 & 3,8 & 17,8 & 6,0 & 0,04 & 0,13 & 2766,7 \\
\hline Média & 1081,4 & 4,4 & 27,9 & 10,3 & 0,52 & 0,67 & 2753,0 \\
\hline Desvio padrão & 679,0 & 0,4 & 9,9 & 3,6 & 0,35 & 0,25 & 1117,2 \\
\hline $\begin{array}{l}\text { Normas } \\
\text { (BRASIL, 2000) }\end{array}$ & --- & --- & Máx. 50,0 & --- & Máx. 0,60 & --- & --- \\
\hline
\end{tabular}




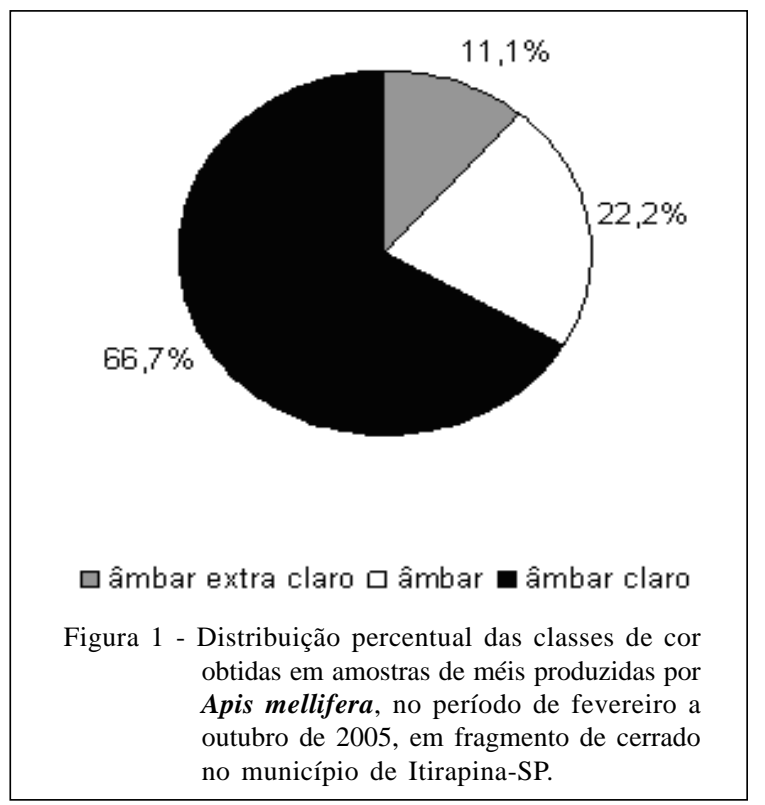

As quantidades de hidroximetilfurfural (HMF) nas amostras analisadas variaram de 1,9 a $19,1 \mathrm{mg} \mathrm{kg}^{-1}\left(8,3 \pm 5,6 \mathrm{mg} \mathrm{kg}^{-1}\right)$, que estão em conformidade com a legislação (BRASIL, 2000), que estabelece o máximo de $60,0 \mathrm{mg} \mathrm{kg}^{-1}$. DAYRELL \& VITAL (1991) afirmam que, em países de clima tropical, as amostras de méis costumam apresentar elevado teor de HMF em função do clima quente, sendo a quantificação deste parâmetro fundamental para a verificação da qualidade do produto. Analisando amostras de méis brasileiros, esses autores encontraram valores variando de 1,1 a $248,2 \mathrm{mg} \mathrm{kg}^{-1}$.

As porcentagens de umidade variaram de $15,8$ a 19,5\% (17,2 $\pm 1,2 \%)$, estando todas abaixo do limite máximo de 20,0\% (BRASIL, 2000). Na literatura são encontrados valores variando de 15,0 (ARRUDA, 2003) a 22,9\% (SODRÉ, 2005) para méis brasileiros de diferentes origens florais e regiões. Em área de cerrado do Estado do Mato Grosso do Sul, esses valores variaram de 15,7 a 26,0\% (VIEIRA, 2005) e em méis do cerrado paulista, entre 16,6 e 20,8\% (ALMEIDAANACLETO \& MARCHINI, 2004).

A condutividade elétrica variou de 227,3 a $1851,3 \mu \mathrm{S}(1081,4 \pm 600,8 \mu \mathrm{S})$, estando bem próximos aos valores obtidos em estudos realizados em outras áreas de cerrado. ALMEIDA-ANACLETO \& MARCHINI (2004), ao analisarem amostras de mel do Estado de São Paulo, e VIEIRA (2005) com amostras de mel do Mato Grosso do Sul encontraram valores de 284,0 a $2200,0 \mu$ S e de 157,7 a 4836,0 $\mu$ S, respectivamente.

Os valores de $\mathrm{pH}$ e acidez encontrados nas amostras variaram de 3,8 a 4,9 $(4,4 \pm 0,4)$ e de 15,1 a $47,0 \mathrm{meq} \mathrm{kg}^{-1}\left(27,9 \pm 9,9 \mathrm{meq} \mathrm{kg}^{-1}\right)$, respectivamente. Para
pH esses resultados são semelhantes aos obtidos por PAMPLONA (1989), que observou uma variação de 3,1 a 5,3 em diferentes méis brasileiros. Para outras áreas de cerrado, a variação encontrada foi muito próxima à variação observada no presente estudo, de 3,4 a 4,9 (VIEIRA, 2005) e de 3,3 a 4,5 (ALMEIDA-ANACLETO \& MARCHINI, 2004). Já para acidez, os valores obtidos estão abaixo do máximo estabelecido pela legislação, que é de 50,0meq $\mathrm{kg}^{-1}$. Na literatura (CAMPOS, 1998; MARCHINI, 2001; SODRÉ, 2000; SODRÉ, 2005) são registrados variações para acidez de 5,0 a 56,0meq kg-1.

$\mathrm{O}$ índice de formol nas amostras analisadas variou de 6,0 a $16,7 \mathrm{~mL} \mathrm{~kg}^{-1}\left(10,3 \pm 3,6 \mathrm{~mL} \mathrm{~kg}^{-1}\right)$, encontrando-se dentro da faixa de variação observada para amostras de méis produzidas no Brasil, que variaram de 4,0 $\mathrm{mL} \mathrm{kg}^{-1}$, determinado em méis do Ceará (SODRÉ, 2005), até 20,5 $\mathrm{mL} \mathrm{kg}^{-1}$ para méis silvestres do Estado de São Paulo (MARCHINI, 2001). Em áreas de cerrado dos Estados de São Paulo (ALMEIDAANACLETO \& MARCHINI, 2004) e Mato Grosso do Sul (VIEIRA, 2005) foram observadas variações de 3,5 a $19,0 \mathrm{~mL} \mathrm{~kg}^{-1}$ e de 5,0 a $16,0 \mathrm{~mL} \mathrm{~kg}^{-1}$, respectivamente.

No presente trabalho, as porcentagens de cinzas se encontraram entre 0,04 e 1,02\% (0,52 $\pm 0,35 \%)$ (Tabela 2), sendo que $44,4 \%$ apresentaram valores acima do limite de 0,60\% estabelecido pela legislação brasileira (BRASIL, 2000). O conteúdo de cinzas no mel é influenciado pela origem botânica, podendo ocorrer variações por fatores relacionados às abelhas, ao apicultor e ao clima da região onde foi produzido (LASCEVE, 1974). Em áreas de cerrado, os valores encontrados para cinzas variaram entre 0,10 e 0,68\% para méis do Mato Grosso do Sul (VIEIRA, 2005) e entre 0,02 e $0,77 \%$ para amostras do cerrado paulista (ALMEIDA-ANACLETO \& MARCHINI, 2004).

No presente trabalho, as porcentagens de proteína variaram de 0,13 a 1,00\% (0,67士0,25\%). Embora a legislação brasileira não exija a análise de material protéico, este parâmetro pode ser utilizado na detecção de adulteração do mel (CRANE, 1975). Os valores de proteínas relatados para méis são bastante variados, no entanto normalmente não ultrapassam 1,00\%. Para amostras de méis silvestres e de eucalipto, esse valor foi de 0,19 e 0,32\%, respectivamente (MARCHINI, 2001). Para amostras do cerrado paulista, a variação foi de 0,07 a 0,49\% (ALMEIDA-ANACLETO \& MARCHINI, 2004), de 0,13 a 0,71\% para méis do Ceará, de 0,11 a $0,37 \%$ para méis do Piauí (SODRÉ, 2005) e entre 0,13 a $0,54 \%$ em méis do cerrado do Mato Grosso do Sul(VIEIRA, 2005).

A viscosidade, que pode ser influenciada por fatores como temperatura, conteúdo de água e alto conteúdo de proteína (CRANE, 1983), apresentou 
valores variando de 1070,0 a $4546,7 \mathrm{mPa} . \mathrm{s}$ (2753,0 $\pm 1117,2 \mathrm{mPa} . \mathrm{s})$. A fonte de néctar explorada pelas abelhas também pode influenciar a viscosidade do mel, como observado por MARCHINI (2001) em amostras de méis de diferentes espécies de Eucalyptus, com valores variando de $9050,0 \mathrm{mPa}$.s para méis de Eucalyptus citriodora, $10700,0 \mathrm{mPa}$.s para $\boldsymbol{E}$. urophylla, 17900,0mPa.s para E. grandis, 19200,0mPa.s para E. camaldulensis e $11550,0 \mathrm{mPa}$.s para $\boldsymbol{E}$. tereticornis. Outros resultados são relatados para amostras de méis de laranjeira do Estado de São Paulo, com valores variando de 98,0 a 5090,0mPa.s (KOMATSU et al., 2002). Para méis do Ceará, esses valores variam de 536,0 a 6770,0mPa.s (SODRÉ, 2005; ARRUDA, 2003), para méis do Piauí, variam de 960,0 a 3436,0mPa.s (SODRÉ, 2005) e para amostras de méis do cerrado do Mato Grosso do Sul, com uma variação de 190,0 a 7040,0mPa.s (VIEIRA, 2005).

Com base nas análises polínicas, foi observado que a vegetação típica deste ecossistema foi pouco representativa nas amostras de méis colhidas nos diferentes meses (Tabela 1), sendo verificada a presença de Eucalyptus sp. como pólen dominante nos meses de fevereiro a julho e o de Citrus sp. no mês de outubro. Esta situação pode ser explicada por uma maior atratividade destes dois cultivos sobre as abelhas, em relação às plantas nativas da área, e por tratar-se de um fragmento de cerrado circundado de grandes áreas reflorestadas e cultivadas.

Das espécies vegetais nativas do cerrado, Eupatorium sp. foi encontrada como pólen acessório no mês de setembro e Serjania sp. nos meses de agosto e setembro. Esta constatação serve de indicativo sobre o potencial destas plantas como fornecedoras de recursos alimentares para as abelhas, dividindo sua preferência com Eucalyptus sp.

\section{CONCLUSÕES}

As características físico-químicas das amostras de méis produzidas estão em conformidade com as normas estabelecidas pela Legislação brasileira, demonstrando que o ambiente de cerrado, mesmo quando apresenta elementos de reflorestamento ou cultivo comercial, proporciona a obtenção de mel de qualidade.

\section{AGRADECIMENTOS}

Os autores agradecem à Fundação de Amparo à Pesquisa do Estado de São Paulo (FAPESP), pelo suporte tecnológico com fornecimento de equipamentos e reagentes, tornando viável o desenvolvimento do trabalho, também agradecem aos responsáveis pela Estação Experimental de
Itirapina, unidade da Divisão de Florestas e Estações Experimentais do Instituto Florestal, pela possibilidade de utilização da área experimental; ao Prof. Dr. Vagner de Alencar Arnaut de Toledo, da UEM, pelo apoio durante a fase experimental, e de análises laboratoriais e ao Conselho Nacional de Desenvolvimento Científico e Tecnológico (CNPq), pela concessão de bolsa de produtividade em pesquisa e bolsa de doutorado a dois autores, o segundo e terceiro respectivamente.

\section{REFERÊNCIAS}

ALMEIDA-ANACLETO, D.; MARCHINI, L.C. Composição físico-química de amostras de méis de Apis mellifera L. provenientes do cerrado paulista. B Indústr anim, Nova Odessa, v.61, n.2, p.161-172, 2004.

ARRUDA, C.M.F. Características físico-químicas e polínicas de amostras de méis de Apis mellifera L., 1758 (Hymenoptera, Apidae) da região da Chapada do Araripe, município de Santana do Cariri, Estado do Ceará. 2003. 86f. Dissertação (Mestrado em Entomologia)- Escola Superior de Agricultura "Luiz de Queiroz”, Universidade de São Paulo.

ASSOCIATION OF OFFICIAL ANALYTICAL CHEMISTS (AOAC). Official methods of analysis. Arlington, 1992. $1141 \mathrm{p}$.

ATAGO Co. Refratômetro para mel. Abelhas, Porto, v.31, n.362/363, p.9, 11-12, 41, 44, 1988.

BOLETIN OFICIAL ESPAÑOL (BOE). Orden de 12 de junio de 1986, de la Presidencia del Gobierno por la que se aprueban los métodos oficiales de anilisis para la miel. Madrid, 1986. N.145.

BRASIL. Ministério da Agricultura. Instrução normativa n.11 de 20 de outubro/2000. Regulamento técnico de identidade e qualidade do mel. Capturado em 30 jan. 2007. On line. Disponível na Internet: http://e-legis.bvs.br/leisref/ public/showAct.php?id=12462.

CAMPOS, G. Melato no mel e sua determinação através de diferentes metodologias. 1998. 178f. Tese (Doutorado em Ciência Animal) - Escola de Veterinária, Universidade Federal de Minas Gerais.

COPERSUCAR. Manual de controle químico da fabricação de açúcar. Piracicaba: Copersucar, 1987. p.1-51.

CRANE, E. Honey: a comprehensive survey. London: Heinemann, 1975. 608p.

CRANE, E. Livro do mel. 2.ed. São Paulo: Nobel, 1983. 226 .

DAYRELL, I.O.; VITAL, N.C. Comparação entre dois métodos oficiais para determinação de hidroxi metilfurfural (HMF) em mel brasileiro. Ciênc Tecnol Aliment, Campinas, v.11, n.1, p.137-141, 1991.

ERDTMAN, G. Pollen morphology and plant taxonomy Angiosperms. Stockholm: Almqvist \& Wiksell, 1952. 539p.

FIORI, A.N.; FIORAVANTI, C. Os caminhos para salvar o cerrado paulista. FAPESP Pesquisa, São Paulo, n.63, p.38-43, 2001.

Ciência Rural, v.38, n.6, set, 2008. 
GIANOTTI, E. Composição florística e estrutura fitossociológica da vegetação e de transição entre cerrado e mata ciliar da Estação Experimental de Itirapina (SP). 1988. 222f. Dissertação (Mestrado em Ecologia) - Instituto de Biologia, Universidade Estadual de Campinas.

KOMATSU, S.S. et al. Análises físico-químicas de amostras de méis de flores silvestres, de eucalipto e de laranjeira, produzidos por Apis mellifera L., 1758 (Hymenoptera: Apidae) no Estado de São Paulo. 2. conteúdo de açúcares e de proteínas. Ciênc Tecnol Aliment, Campinas, v.22, n.2, p.143-146, 2002.

LASCEVE, G.; GONNET, M. Analyse par radioactivation du contenu mineral d'un mile. Possibilité de préciser son origine géographique. Apidologie, Les Ulis, v.5, n.3, p.201-223, 1974.

MARCHINI, L.C. Caracterização de amostras de méis de Apis mellifera L., 1758 (Hymenoptera: Apidae) do Estado de São Paulo, baseada em aspectos físico-químicos e biológicos. 2001. 83f. Tese (Livre Docência) - Escola Superior de Agricultura "Luiz de Queiroz”, Universidade de São Paulo.

MARCHINI, L.C. et al. Mel brasileiro: composição e normas. Ribeirão Preto: ASP, 2004. 131p.

MORAES, R.M.; TEIXEIRA, E.W. Análise do mel. Pindamonhangaba: SN, 1998. 41p. (Manual técnico).

PAMPLONA, B.C. Exame dos elementos inorgânicos encontrados em méis de Apis mellifera e suas relações físico-biológicas. 1989. 131f. Dissertação (Mestrado em Entomologia) - Instituto de Biociências, Universidade de São Paulo.

PERSANO-ODDO, L.P. et al. Characterization of unifloral honey. Apidologie, Les Ulis, v.26, p.453-465, 1995.

PREGNOLATO, W.; PREGNOLATO, N.P. Métodos químicos e físicos para análise de alimentos. In: PREGNOLATO, W.; PREGNOLATO, N.P. (Coord.). Normas analíticas do Instituto Adolfo Lutz. 3.ed. São Paulo: Instituto Adolfo Lutz, 1985. V.1, 533p.
REIS, M.S.; MARIOT, A. Diversidade natural e aspectos agronômicos de plantas medicinais. In: SIMÕES, C.M.O. et al. (Org.). Farmagnosia: da planta ao medicamento. Florianópolis/ Porto Alegre: UFSC / UFRGS, 1999. p.39-60.

SILVA, D.J.; QUEIROZ, A.C. Determinação do nitrogênio total e da proteína bruta. In: SILVA, D.J.; QUEIROZ, A.C. Análise de alimentos: métodos químicos e biológicos. 3.ed. Viçosa: UFV, 2002. p.57-75.

SODRÉ, G.S. Características físico-químicas e análise polínica de amostras de méis de Apis mellifera L., 1758 (Hymenoptera: Apidae) da região litoral norte do estado da Bahia. 2000. 83f. Dissertação (Mestrado em Entomologia) - Escola Superior de Agricultura "Luiz de Queiroz”, Universidade de São Paulo.

SODRÉ, G.S. Características físico-químicas, microbiológicas e polínicas de amostras de méis de Apis melliferaL., 1758 (Hymenoptera: Apidae) dos estados do Ceará e Piauí. 2005. 127f. Tese (Doutorado em Ciências Biológicas)- Escola Superior de Agricultura “Luiz de Queiroz”, Universidade de São Paulo.

UÑATES, M.A. et al. Estúdio físico-químico de mieles de la província de San Luís- República Argentina. Arch Latinoam Nutr, Caracas, v.49, n.2, p.193-196, 1999.

VIDAL, R.; FREGOSI, E.V. Mel: características, análises físico-químicas, adulterações e transformações. Barretos: Instituto Tecnológico Científico "Roberto Rios”, 1984. 95p.

VIEIRA, G.H.C. Análise faunística de abelhas (Hymenoptera: Apoidea) e tipificação dos méis produzidos por Apis mellifera $\mathrm{L}$., em área de cerrado do município de Cassilândia/MS. 2005. 97f. Tese (Doutorado em Ciências Biológicas) - Escola Superior de Agricultura "Luiz de Queiroz”, Universidade de São Paulo.

WHITE JÚNIOR, J.W. Honey. Advances in Food Research, New York, v.22, p.287-374, 1978. 